\title{
THE EFFECTS OF WAVE-ACTION ON THE DISTRIBUTION AND NUMBERS OF THE COMMONER PLANTS AND ANIMALS LIVING ON THE PLYMOUTH BREAKWATER
}

\author{
By A. J. Southward and the late J. H. Orton, F.R.S.
}

\author{
(Text-figs. I-7)
}

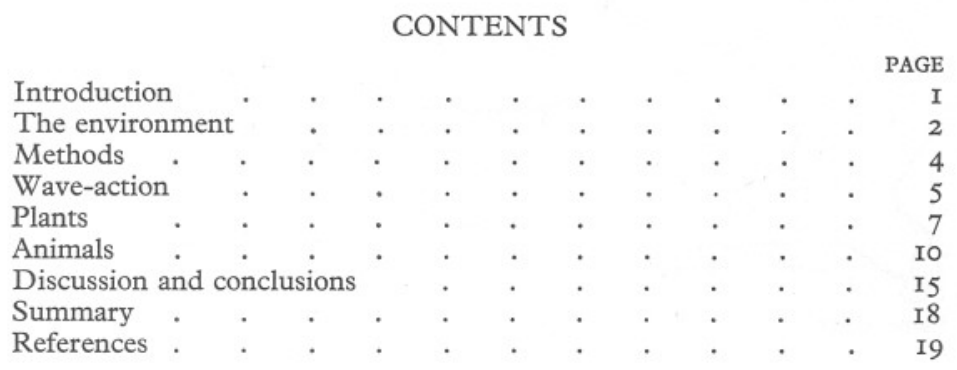

\section{INTRODUCTION}

The breakwater in Plymouth Sound offers a simple case of two adjacent populations of intertidal organisms subjected to quite different degrees of exposure to wave-action. The other environmental factors, with a few exceptions, are approximately the same each side, and the effects of the waveaction should be clearly demonstrable.

Previous experience in the Isle of Man (Southward, 1953) has proved that evidence of variation in the numbers of the plants and animals is as important as variation in their zonation, and that the numbers may, in fact, show the greater changes in relation to differing degrees of exposure to wave-action. The work was planned on a quantitative basis, and the breakwater proved a fortunate choice, since it offers relatively uniform slopes throughout the greater part of the intertidal zone. The latter factor is almost a necessity for a quantitative study, but a quality lacking in most of the rocks exposed in the Plymouth area.

The investigation was suggested by Prof. Orton, and was planned and begun as a joint study with the aid of a grant from the E. T. Browne Fund of the Royal Society. Various factors intervened, not the least of which were delays due to inclement weather, and most of the field work was carried out by 
A. J. S. alone, in September I95I. This account was prepared by A. J. S. and revised by Prof. Orton shortly before his death.

We are indebted to Mr F. S. Russell, F.R.S., and to various members of the staff of the Marine Biological Association for assistance, and to Dr R. G. Evans for helpful criticism of the typescript.

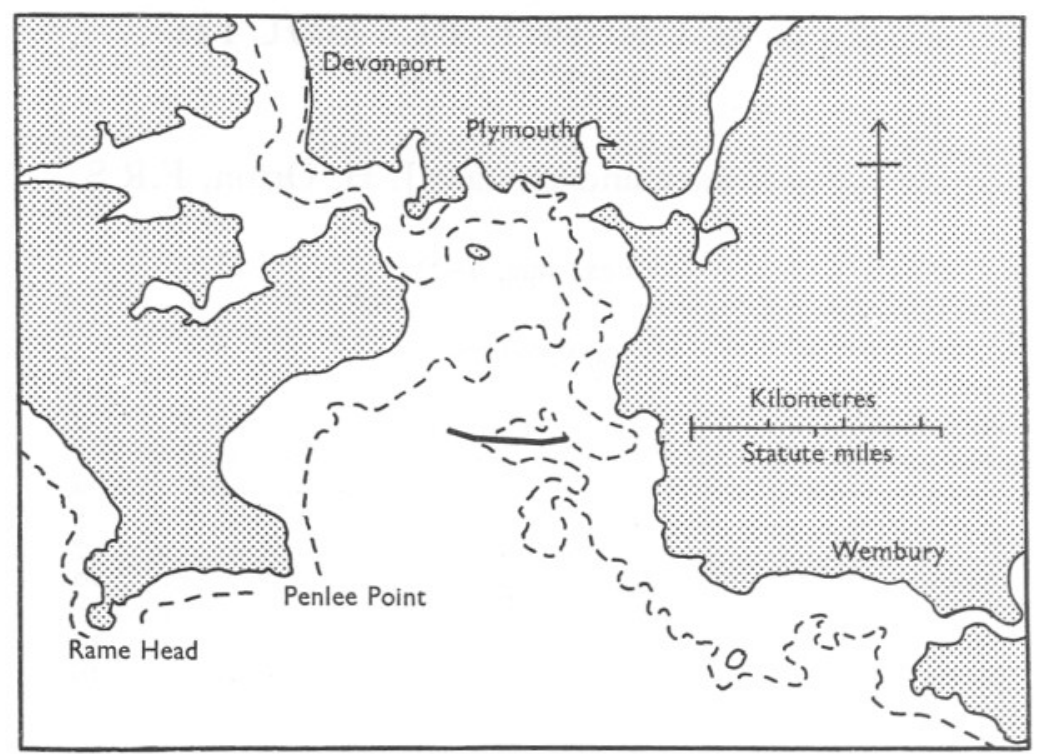

Fig. I. Map of the Plymouth area showing the position of the breakwater. - - approx. 5 fathom $(9 \mathrm{~m}$.) line.

\section{THE ENVIRONMENT}

The general environment of the Plymouth area has been discussed by Orton (I920), Colman (I933) and Evans (I947 b), and the main features of the breakwater have been described by Lysaght (I94I). It is therefore only necessary to mention certain factors of importance to this study.

Substratum. The main constituent of the breakwater is a local limestone, and the northern side, down to low-water neap level, consists entirely of blocks of this material cemented together. From low-water neaps down, however, the north side consists of limestone and cement rubble of varying size: some of the larger masses may project as high as mid-tide level (Fig. 2).

On the southern side of the breakwater, the sharp ledges at each end (Fig. 2, sections $A$ and $E$ ), the ledge at low-water neaps (sections $C$ and $D$ ) and various other isolated parts (particularly on section $B$ ) are faced with granite. The granite frequently stands proud of the limestone by as much as $5 \mathrm{~cm}$., indicating the extent to which the latter has eroded, and in places, especially towards the western end, this erosion has produced a somewhat irregular 


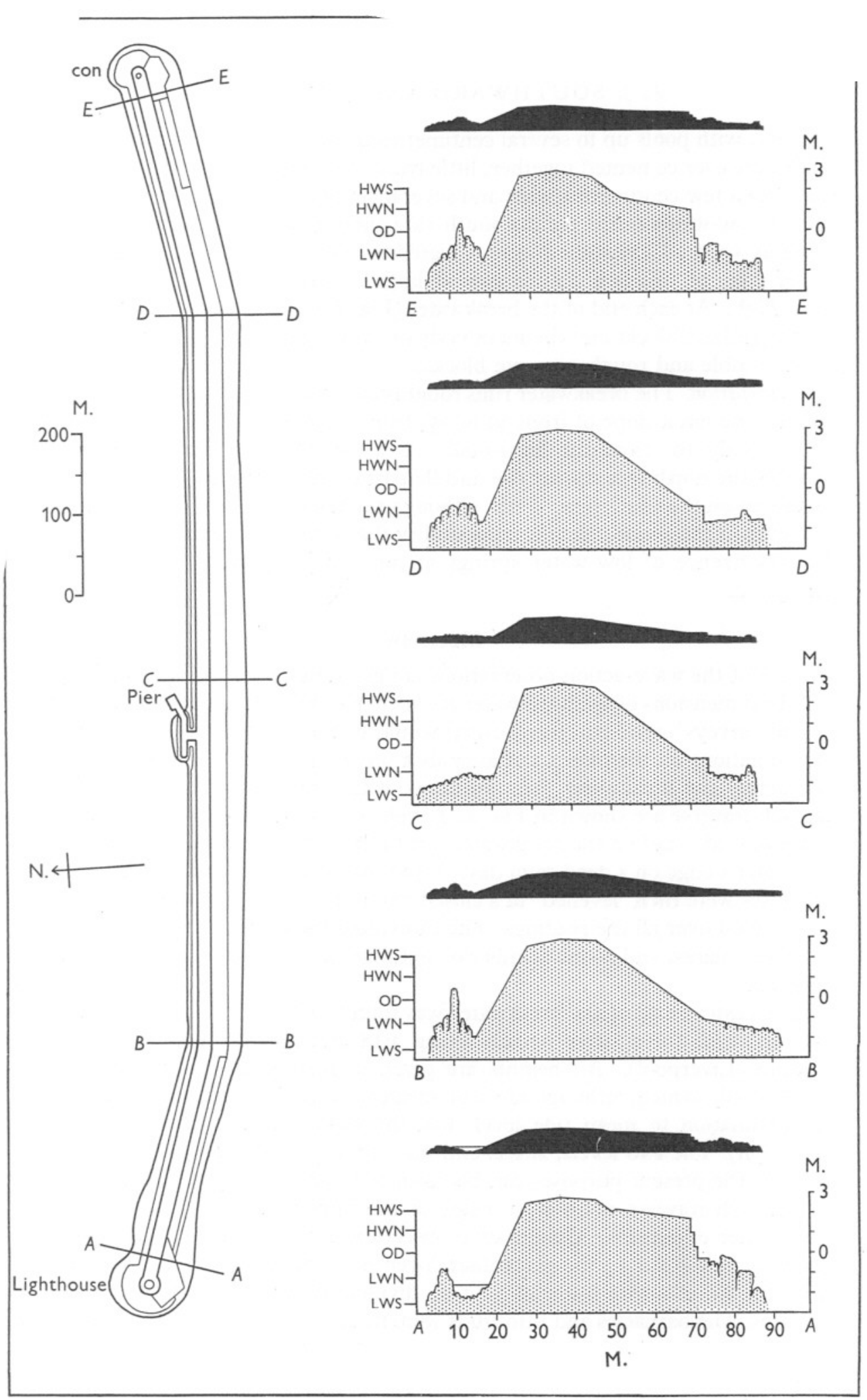

Fig. 2. Plan of the breakwater showing the traverses $(A-A$ to $E-E)$ and sections across them. The sections in black show the true profiles, while those stippled have their vertical scale exaggerated (five times the horizontal scale) to bring out the salient features. 
surface, with pools up to several centimetres deep. If the blocks on the south side were ever cemented together, little trace of it remains, and there are deep crevices a few centimetres wide and several centimetres deep, between them. Below low-water neaps on the south side there is a gently sloping layer of roughly squared limestone blocks, covered with concrete in places, and at the outer edge of this is a double row of large concrete blocks, approximately $2 \mathrm{~m}$. high. At each end of the breakwater (Fig. 2, sections $A$ and $E$ ) the space between these blocks and the main body of the breakwater is filled with limestone rubble and rough concrete blocks.

Orientation. The breakwater runs roughly east-west (Fig. I), and the northfacing side has a slope of from 30 to $35^{\circ}$ from the horizontal, while the south face is only $10^{\circ}$ from the horizontal. As a consequence, the sunlight that reaches the north face during the middle part of the day will be more oblique than that on the south face. Thus, although the north face cannot be regarded as being in the shade, there is a possibility that some of the adverse effects of the occurrence of low-water springs at midday (see Orton, 1920) may be mitigated.

\section{METHODS}

Details of the wave-action observations are given in a separate section (p. 5). The dimensions of the breakwater are such that the methods used previously ('grid surveys', see Southward, I953) would be most impractical, and for the investigations on the plants and animals a series of five traverses was marked out across the breakwater. The positions of the traverses and cross-sections at each traverse are shown in Fig. 2. Levels were transferred from a recently surveyed tide-staff on the breakwater fort to the breakwater pier, by means of the water's edge on a dead calm day. Fixed marks at the highest points of the traverses were then 'levelled' in a closed circuit from the pier, the error being distributed over all the readings. The individual traverses were levelled from the fixed marks, and as the number of sightings was small, the error could be ignored.

The eastern end of the breakwater was found to be $0.3 \mathrm{~m}$. higher than the western end, the relative heights being 3.18 and $2.88 \mathrm{~m}$. above Ordnance Datum (Liverpool). All heights are given in metres above or below O.D. (Liverpool), which, although not true mean sea level, is at Plymouth a better approximation to mean tide level than the more recently established O.D. (Newlyn). The two levels, M.T.L. and o.D. (Liverpool) differ by only $0.07 \mathrm{~m}$., and for the present purposes can be taken to be the same (see Table I).

On each traverse notes were made of the upper and lower limits of the commoner organisms. Quantitative observations were made at each $0.5 \mathrm{~m}$. above or below M.T.L., the percentage cover of the plants being first estimated with the aid of a wire frame of $\mathrm{I} \times \mathrm{I} \mathrm{m}$. divided up into a hundred decimetre squares. The barnacles and littorinids were then counted on several decimetre 
squares, or the whole metre square if sparse, and finally the limpets and topshells were removed from the whole or half of the metre square for sorting. The length of the limpet shells was later measured to the nearest millimetre.

Owing to the broken nature of the region at L.W.N. on the north side the quantitative observations were not completed on certain traverses. Traverse $A$ north side ended in a pool, and was not carried below M.L.W.N.

The animals and plants in the deep crevices between the blocks and in the pools were not included in the survey.

\section{Table I. Tide Levels for Plymouth, Based on the Admiralty TIDE TABLES (I95I)}

\begin{tabular}{|c|c|c|c|c|c|c|c|}
\hline \multirow[b]{2}{*}{ Levels } & \multirow{2}{*}{$\begin{array}{l}\text { Abbreviations } \\
\text { used in } \\
\text { text }\end{array}$} & \multicolumn{2}{|c|}{$\begin{array}{l}\text { Height } \\
\text { relative } \\
\text { to C.D. } \\
\text { (Devonport) }\end{array}$} & \multicolumn{2}{|c|}{$\begin{array}{l}\text { Height } \\
\text { relative } \\
\text { to o.D. } \\
\text { (Liverpool) }\end{array}$} & \multicolumn{2}{|c|}{$\begin{array}{l}\text { Height } \\
\text { relative } \\
\text { to o.D. } \\
\text { (Newlyn) }\end{array}$} \\
\hline & & Feet & Metres & Feet & Metres & Feet & Metres \\
\hline $\begin{array}{l}\text { Extreme high-water } \\
\text { springs }\end{array}$ & E.H.W.S. & $17 \cdot 0$ & $5 \cdot 2$ & $8 \cdot 5$ & $2 \cdot 6$ & $8 \cdot 0$ & $2 \cdot 4$ \\
\hline $\begin{array}{l}\text { Mean high-water } \\
\text { springs }\end{array}$ & M.H.W.S. & $15 \cdot 70$ & $4 \cdot 79$ & $7 \cdot 28$ & $2 \cdot 22$ & $6 \cdot 78$ & $2 \cdot 07$ \\
\hline $\begin{array}{l}\text { Mean high-water } \\
\text { neaps }\end{array}$ & M.H.W.N. & I $2 \cdot 25$ & $3 \cdot 72$ & $3 \cdot 83$ & $I \cdot I 5$ & $3 \cdot 33$ & $I \cdot 00$ \\
\hline $\begin{array}{l}\text { Ordnance datum } \\
\text { (Newlyn) }\end{array}$ & O.D. & $8 \cdot 92$ & $2 \cdot 72$ & 0.50 & 0.15 & 0 & 0 \\
\hline $\begin{array}{l}\text { Ordnance datum } \\
\text { (Liverpool) }\end{array}$ & O.D. & $8 \cdot 42$ & $2 \cdot 57$ & ० & ० & -0.50 & -0.15 \\
\hline Mean tide level & M.T.L. & $8 \cdot 20$ & $2 \cdot 50$ & -0.22 & -0.07 & -0.72 & -0.22 \\
\hline Mean low-water neaps & M.L.W.N. & $4 \cdot 60$ & $\mathrm{I} \cdot 40$ & $-3 \cdot 82$ & $-I \cdot I 6$ & $-4 \cdot 32$ & $-I \cdot 3 I$ \\
\hline Mean low-water springs & M.L.W.S. & $0 \cdot 18$ & 0.06 & $-8 \cdot 24$ & $-2.5 I$ & $-8 \cdot 74$ & $-2 \cdot 66$ \\
\hline Chart datum & C.D. & 0 & 0 & $-8 \cdot 42$ & -2.57 & $-8 \cdot 92$ & $-2 \cdot 72$ \\
\hline $\begin{array}{l}\text { Extreme low-water } \\
\text { springs }\end{array}$ & E.L.W.S. & $-I \cdot 6$ & -0.5 & -10.0 & $-3 \cdot 0$ & -10.5 & $-3 \cdot 3$ \\
\hline
\end{tabular}

\section{WAVE-ACTION}

For the purpose of the present study, significant wave-action was defined as the occurrence of waves washing over the top of the breakwater at, or before, high water. With the tide at M.H.W.S. this requires a minimum height of wash of $0.6 \mathrm{~m}$. above the true tide height at the western end of the breakwater, but at neap tides, of course, much greater wash is required. However, during rough weather the observations had to be made from the land (with the aid of field-glasses), as it was impossible to reach the breakwater, and no other criterion of wave-action was feasible over the distance involved $(3.5 \mathrm{~km}$.). During a period of 28 days' observations it was found that practically all winds with a velocity of Io m.p.h. (I6 km./hr.) or more, blowing from the sector W.-S.-S.E. were associated with waves breaking over the top of the breakwater. Some of the more extreme examples of the observations are shown in Table II: nearly all of these were recorded from the shelter of the laboratory. 
By applying the the results of the observations to wind records it is possible to produce an approximate exposure index. From Table III, columns I and 2, the values for 1950 and 1951 were 38 and $32 \%$ respectively. These figures are similar to those arrived at by Lysaght (I94I), who, however, considered the sector S.W.-S.-S.E. to be critical (Table III, column 3).

\section{Table II. Some of the More Extreme Examples of Wave-ACtion ON THE BREAKWATER}

\begin{tabular}{|c|c|c|c|c|c|c|c|c|}
\hline \multirow[b]{2}{*}{$\begin{array}{r}\text { Date } \\
(\text { I95I) }\end{array}$} & \multirow[b]{2}{*}{$\begin{array}{c}\text { Wind } \\
\text { direction } \\
\text { and velocity } \\
\text { (m.p.h.) at } \\
\text { o9.00 hr. }\end{array}$} & \multirow{2}{*}{$\begin{array}{l}\text { Maximum } \\
\text { wind } \\
\text { velocity } \\
\text { (gusts } \\
\text { in m.p.h.) } \\
\text { during } \\
\text { succeeding } \\
24 \mathrm{hr} \text {. }\end{array}$} & \multicolumn{3}{|c|}{ West end } & \multicolumn{3}{|c|}{ East end } \\
\hline & & & $\begin{array}{l}\text { Time of } \\
\text { waves } \\
\text { starting } \\
\text { to wash } \\
\text { over }\end{array}$ & $\begin{array}{l}\text { Predicted } \\
\text { height of } \\
\text { tide at the } \\
\text { time (metres } \\
\text { relative to } \\
\text { o.D.) }\end{array}$ & $\begin{array}{c}\text { Calculated } \\
\text { minimum } \\
\text { height } \\
\text { of wash } \\
\text { (m.) }\end{array}$ & $\begin{array}{l}\text { Time } \\
\text { of waves } \\
\text { starting to } \\
\text { wash over }\end{array}$ & $\begin{array}{l}\text { Calculated } \\
\text { height of } \\
\text { tide at the } \\
\text { time (metres } \\
\text { relative } \\
\text { to o.D.) }\end{array}$ & $\begin{array}{c}\text { Calculated } \\
\text { minimum } \\
\text { height of } \\
\text { wash (m.) }\end{array}$ \\
\hline 26 Aug. & W.S.W. I6 & 42 & 09.30 & $\circ$ & 2.8 & \multirow{2}{*}{\multicolumn{3}{|c|}{$\begin{array}{l}\text { No wash, even at high water } \\
\text { No wash, even at high water }\end{array}$}} \\
\hline 27 Aug. & S.W. I8 & 35 & II.00 & 0.4 & $2 \cdot 3$ & & & \\
\hline 28 Aug. & S.S.W. 23 & 48 & II. 45 & 0.3 & $2 \cdot 4$ & I3.00 & I. 3 & $\mathrm{I} \cdot 7$ \\
\hline 29 Aug. & S.S.W. 20 & 44 & 12.00 & -0.2 & $3 \cdot 0$ & & $\mathrm{I} \cdot 6$ & $I \cdot 4$ \\
\hline I3 Sept. & S.S.W. 4I & 57 & II. 45 & $-I \cdot 3$ & $4 \cdot I$ & 12.30 & -0.6 & $3 \cdot 6$ \\
\hline I4 Sept. & S.S.W. I9 & 52 & 13.50 & -0.2 & $3 \cdot 0$ & \multicolumn{3}{|c|}{ No observation } \\
\hline
\end{tabular}

\section{Table III. Distribution of Winds at Plymouth}

\begin{tabular}{|c|c|c|c|}
\hline \multirow[b]{2}{*}{ Month } & \multicolumn{2}{|c|}{$\begin{array}{l}\text { Percentage days of wind } \\
\text { blowing from the sector } \\
\text { W.-S.-S.E. with a velocity } \\
\text { of Io m.p.h. or more }\end{array}$} & \multirow{2}{*}{$\begin{array}{l}\text { Percentage of winds (all } \\
\text { velocities) blowing from the } \\
\text { sector S. W.-S.-S.E., for the } \\
\text { period I893-I922 (from } \\
\text { Lysaght, I94I, p. 43) }\end{array}$} \\
\hline & I950 & I95I & \\
\hline Jan. & 32 & 29 & 33 \\
\hline Feb. & 64 & 39 & 34 \\
\hline Mar. & 45 & 42 & 32 \\
\hline April & 30 & 27 & 30 \\
\hline May & I6 & I6 & 35 \\
\hline June & 47 & 40 & 38 \\
\hline July & 35 & Io & 36 \\
\hline Aug. & 68 & 55 & 40 \\
\hline Sept. & 43 & 43 & 30 \\
\hline Oct. & 39 & 6 & 32 \\
\hline Nov. & 20 & 40 & 26 \\
\hline Dec. & I6 & 35 & 35 \\
\hline Year & 38 & 32 & 33 \\
\hline
\end{tabular}

All these exposure indices seem low compared with similarly derived indices for other places (e.g. $70 \%$ at Port St Mary, Isle of Man, see Southward, 1953), but there is no evidence that the breakwater is any less liable to waveaction. In spite of the wind and wave records there were only 3 days out of the 28 without any wave-action on the south side, and it would seem that refracted waves and swells play a much bigger part in the wave-action on the breakwater than at Port St Mary. There can be no precise comparison of the two places without long-period wave recordings. 
In comparing the wave-action on the north and south faces of the breakwater we are on a firmer basis. It has already been pointed out that, during the period of wave-action observations, there were only 3 days when there was no appreciable wave-action on the south side; in the remaining 25 days the wave-action produced a wash of at least $0.3 \mathrm{~m}$. above true tide height, if not more. On the north face, however, even during north-easterly winds reaching gale force at times, the wash was not seen to exceed $0.3 \mathrm{~m}$., which is less than a tenth of the maximum wash observed on the south side.

It must be noted that, although the north face would appear to be almost completely sheltered from the mechanical effects of wave-action, it is wetted by wash when waves break over the top of the breakwater from the south side. This may accentuate the possible effects (noted on p. 4) of the obliquity of the sunlight received by the north face.

From the topography it might be expected that the eastern end of the breakwater would experience greater wave-action than the western end, which appears to be sheltered, to some extent, by Rame Head and Penlee Point (Fig. I). However, this was not the case, and the observations show that there was considerably more wave-action on the western end than on the eastern end. The eastern end is only $0.3 \mathrm{~m}$. higher than the western end, yet, on several occasions it was observed that the waves did not begin to wash over it until the tide had risen by from 0.5 to $\mathrm{r} \cdot 6 \mathrm{~m}$. above the level at which it stood when waves began washing over the western end (see Table II). On two occasions waves began washing over the western end more than $2 \mathrm{hr}$. before high water, but there was no wash at the eastern end even at high water.

The evidence thus indicates that the wave-action at the western end may be some 10-40\% greater than at the eastern end of the breakwater. It is possible that the deeper water at the western end of the breakwater, which stands in $\mathrm{I} 2-\mathrm{I} 5 \mathrm{~m}$. of water at low tide, may allow the closer approach of larger waves, with consequently greater wash on breaking. The eastern end stands in only 6-9 m. of water at low tide, and may be sheltered by the shoals to the south (Fig. I).

\section{Plants}

At first impression there seemed to be a marked difference between the two sides of the breakwater, the south side appearing to be practically bare of algae, while the north face bore a comparatively dense population. In general, further investigation confirmed this view, but the population on the south side was greater than expected.

The species dealt with are described below: their nomenclature follows that of Newton (I93I). The calcareous algae of the genera Lithothamnion, Lithophyllum and Melobesia were not identified and are referred to collectively as 'lithothamnia'. 
Enteromorpha sp. Slight patches of Enteromorpha mixed with filamentous green algae occurred on the northern slope between M.H.W.N. and M.T.L. These patches were commonest towards the western end (traverses $A$ and $B$ ) but did not exceed $20 \%$ cover. On the south side Enteromorpha was present all along the ledge just above M.L.W.N., but was commonest between traverses $C$ and $D$; many of the limpets had a dense growth on their shells.

Laminaria saccharina and Saccorhiza polyschides (bulbosa) had similar distributions, at, and below, M.L.W.S. all along the northern side: on the south side they were restricted to the larger crevices between the rough blocks below L.W.N., occurring as high as $0.5 \mathrm{~m}$. above M.L.W.S. This distribution confirms previous evidence (Evans, $1947 b$ ) that these species are generally restricted to places sheltered from wave-action. However, Laminaria saccharina seems to require a certain amount of water movement.

L. digitata. While some young plants of this species occurred as high as M.L.w.N. among the Himanthalia on the south side, the main upper limit, defined here as the zone of $50 \%$ or more cover, was a trifle higher on the north face, where it began at $0.4 \mathrm{~m}$. above M.L.W.S. compared with M.L.W.S. on the south side. To some extent, this bears out a tendency, noted by Evans $(1947 b)$ and Southward (1953), for the main upper limit of Laminaria on steep or broken shores to be higher in sheltered places. However, on both sides of the breakwater there was practically $100 \%$ cover below M.L.W.S.

Fucus spiralis. As shown in Fig. 3, this species was well represented on the north side, where it occurred from M.H.w.S. down to M.T.L. The maximum cover was found at M.H.W.N. and just above, increasing from $20 \%$ on traverse $A$ to over $50 \%$ on traverse $E$. It was poorly represented on the south side, only a few tufts being found on traverse $A$, and nowhere exceeded $6 \%$ cover. The zone varied quite widely on the south side but was always narrower than that on the north side. It is worth noting that on the north side of traverses $A, B$ and $C$, the lowermost plants occurred side by side with the uppermost plants of $F$. serratus. This overlapping of the two species is not recorded by Colman (1933) or Evans (I947 b), and has not been noticed in the Isle of Man, but may occur in Cardigan Bay (Evans, I947a). It is possibly due to an unusually low lower limit of the spiralis, which itself may be due to the absence of Ascophyllum.

Fucus vesiculosus (Fig. 3). As might be expected from the known tolerance by this species of considerable wave-action (Kitching, I935; Evans, I947 $b$; Southward, 1953), the differences between the populations on the north and south sides of the breakwater were much less than those of the other species of Fucus. In general, the cover was lower on the south side where it reached a maximum of $14 \%$ compared with up to $26 \%$ on the north side, but on traverse $A$ the cover on either side did not exceed $2 \%$. The upper and lower limits varied widely, the narrowest zone being found on the north side of traverse $A$, from $0.4 \mathrm{~m}$. above M.T.L. to M.L.W.N. In other places, such as the 
south side of traverse $B$, and the north side of traverse $E$, the species occurred up to M.H.W.N.

F. serratus (Fig. 3). This species is usually found higher up the shore in sheltered situations (Evans, I947b; Southward, I953). On the breakwater, the main upper limit on the north side was at approximately M.T.L., compared with about M.L.W.N. on the south side. With the exception of traverse $B$, the population was denser on the north side, where it exceeded $90 \%$ cover in places, compared with a maximum of $40 \%$ on the south side.

Ascophyllum nodosum was not found.

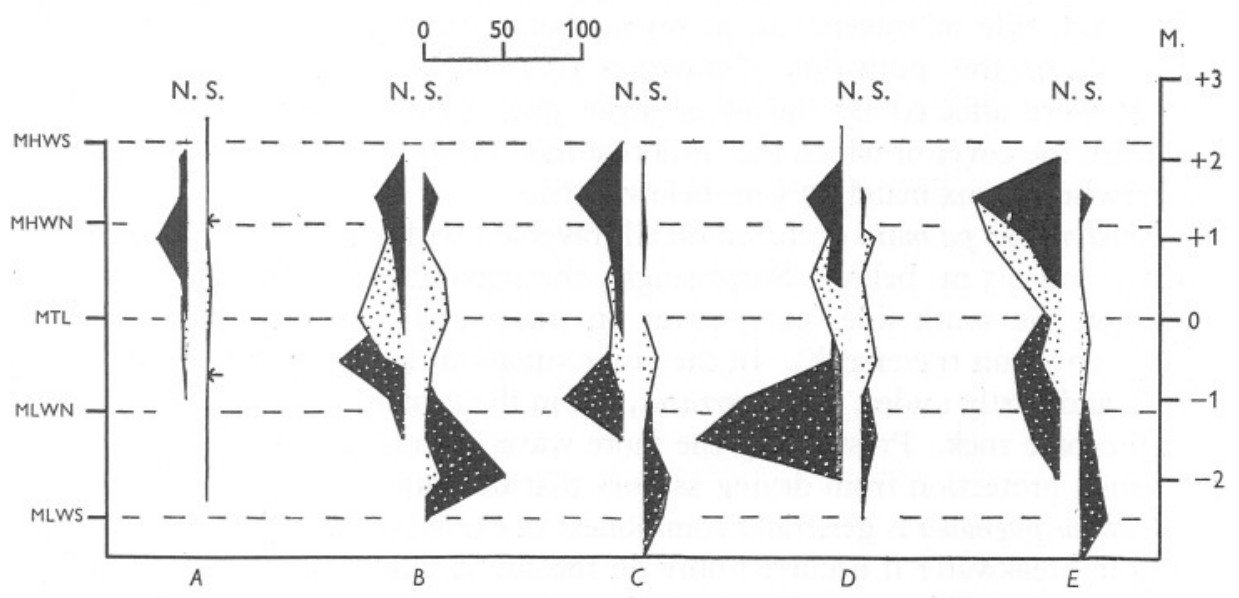

Fig. 3. The distribution of three species of Fucus on the breakwater. On the south side of traverse $A$ the limits between the species are marked by arrows; on the north side of $A$, $F$. serratus could not be investigated and is not shown. On this, and subsequent diagrams, frequency polygons for the north and south sides of the traverses are indicated by the letters N. and S. respectively. 물, F. spiralis; 圆, F. vesiculosus; 闵, $F$. serratus. The scale denotes percentage cover.

Pelvetia canaliculata was not observed on any of the traverses other than the north side of $C$, where it occupied a narrow zone from $0.8 \mathrm{~m}$. above M.H.W.N. to $0.3 \mathrm{~m}$. above M.H.W.N., and reached $36 \%$ cover. Traverse $C$ is very near the pier (see Fig. 2) and at high water is probably the most sheltered region of the whole breakwater. A few isolated tufts of Pelvetia were seen on the south side, between traverses $B$ and $C$.

Himanthalia lorea formed a well-defined belt on both sides of the breakwater, from about $0.5 \mathrm{~m}$. above M.L.W.N. down to almost M.L.W.S. On both sides it achieved 100\% cover in places, but the region of maximum cover was higher on the north side, at approximately M.L.W.N., than on the south side, at $0.8 \mathrm{~m}$. below this level. The species was least developed on the south side of traverse $A$, where it did not exceed I2 $\%$ cover. 
Porphyra umbilicalis. A few plants of this species, presumably the remnants of the settlement in the autumn of the previous year, were present all along the south side between M.H.W.S. and M.H.W.N., and at M.L.W.N. They were commonest just above M.H.W.N., where they reached $5 \%$ cover. A few tufts also occurred on the north side of traverse $A$ at M.H.W.N.

'Lithothamnia'. The upper limit of the 'lithothamnia' and the associated Corallina, excluding pools and wet places, usually corresponds to the lower limit of the barnacles: on steep slopes or broken shores these limits are usually lower in the more wave-beaten places (Southward, I953). This was the case on the breakwater, the lowest position of the limits being found on the south side of traverse $A$, at $0.5 \mathrm{~m}$. below M.L.W.N., compared with at M.L.W.N. on the south side of traverses $C, D$ and $E$. On the north side the limits were affected by the other algae present, especially Fucus serratus, beneath the cover of which the 'lithothamnia' occurred up to M.T.L., but was otherwise approximately $0.5 \mathrm{~m}$. below M.T.L.

Rhodymenia palmata occurred on all traverses, with an upper limit between M.T.L. and $0.5 \mathrm{~m}$. below. Surprisingly, the maximum densities were found both on the south side (20\% cover on traverse $A$ ) and on the north side $(20 \%$ cover on traverse $E$ ). In the latter situation the species was associated with, and partly under, Fucus serratus, but in the former it was largely present on the bare rock. Presumably the more wave-beaten situation $(A)$ provides as much protection from drying as does that beneath Fucus.

Lichina pygmaea is generally commonest in exposed places (Evans, $1947 b$ ). On the breakwater it occurred only on the south side, but was quite sparse, not exceeding $4 \%$ cover. The zone, from E.H.W.S. to $0.3 \mathrm{~m}$. above M.H.W.N., is narrow compared with other places in the Plymouth area where it may extend to M.T.L. (Colman, 1933; Evans, 1947b). The sparseness and restricted zone suggest that the breakwater is an unsuitable habitat for the species, possibly due to the smooth nature of the limestone blocks.

\section{ANIMALS}

The nomenclature of the animals is based on that of the Plymouth Marine Fauna (Marine Biological Association, I93I), with the following exceptions: Patella intermedia Jeffreys $\mathrm{I} 865=P$. depressa Pennant 1777 (see FischerPiette, I938, I948); $P$. aspera Lamarck $\mathrm{I} 8 \mathrm{I} 9=P$. athletica Bean $\mathrm{I} 844$ (see Fischer-Piette, I938, I948); Littorina saxatilis Olivi $1792=$ L. rudis Maton I797 (see Colman, I932).

Chthamalus stellatus. On all but the gentlest of slopes this species would appear to show the same relation to wave-action as does Balanus balanoides, i.e. an increase in exposure raises the upper limit, lowers the lower limit, and increases the population density (Hatton \& Fischer-Piette, 1932; Moore, I935; Southward, 1953). On the breakwater this was true of the southern face 
as compared with the northern face, but the difference in number was much more noticeable than the differences in the upper and lower limits (Fig. 4). Thus, the upper limit on the north side was at approximately E.H.w.S. (0.3 m. above M.H.W.S.). On the south side the species did not occur any higher than the general upper surface of the breakwater ( $0.6 \mathrm{~m}$. above E.H.W.S.), in spite of the numerous structures, such as shelters and blockhouses, which extended above this height. The lower limit on the south side varied from M.L.W.N. at the eastern end to $0.4 \mathrm{~m}$. below this level at the western end. This is some $0.7-\mathrm{I} \cdot \mathrm{I} \mathrm{m}$. below the lower limit on the northern side, which was roughly 0.5 m. above M.L.W.N. (see Fig. 4).

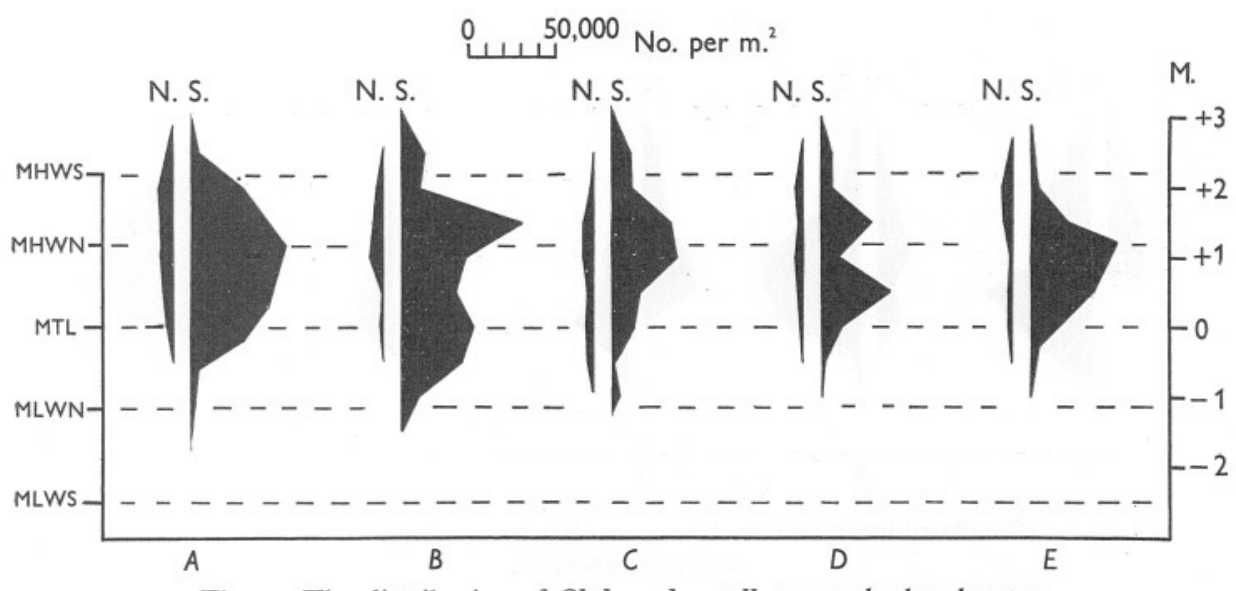

Fig. 4. The distribution of Chthamalus stellatus on the breakwater.

The counts showed much greater differences between the two sides of the breakwater. On each traverse, at the region of maximum abundance (about M.H.W.N.), the numbers of Chthamalus on the south side were over five times as great as those on the north side. The greatest number found on the north side was a mere $8000 / \mathrm{m} .{ }^{2}$, compared with a maximum of $68,000 / \mathrm{m} .{ }^{2}$ found on the south side. However, the latter figure refers to a granite substratum: on limestone the numbers did not exceed $40,000 / \mathrm{m} .{ }^{2}$, and were always lower than on the nearby granite. This difference in density of population between the two types of rock seems to be a fairly general phenomenon, and in this case may be related to the rougher surface of the granite.

It must be noted that on both sides of the breakwater the barnacle population was greater at the western end, although this was most marked on the south side (Fig. 4).

Balanus balanoides. At the time of the field work this barnacle had practically disappeared from the Plymouth area (Southward \& Crisp, I952). Isolated specimens were found on the south side of the breakwater, between M.T.L. 
and M.L.w.N. on traverses $A, B$ and $C$. The numbers did not exceed $2 / \mathrm{m}^{2}$, and the distribution was very erratic.

$B$. perforatus was found on both sides of the breakwater, between $0.8 \mathrm{~m}$. above, and $0.8 \mathrm{~m}$. below, M.L.W.N. The numbers were somewhat greater on the south side, with a maximum of $\mathrm{I} 6 / \mathrm{m} .{ }^{2}$, compared with up to $6 / \mathrm{m} .{ }^{2}$ on the north side.

B. crenatus occurred on the south side from $0.8 \mathrm{~m}$. below M.L.W.N. to the lowest level investigated (E.L.W.S.), and was commonest towards the western end where it reached a density of up to $40 / \mathrm{m}^{2}$ on traverse $A$. On the north side it was noticed only on the piles of the pier.

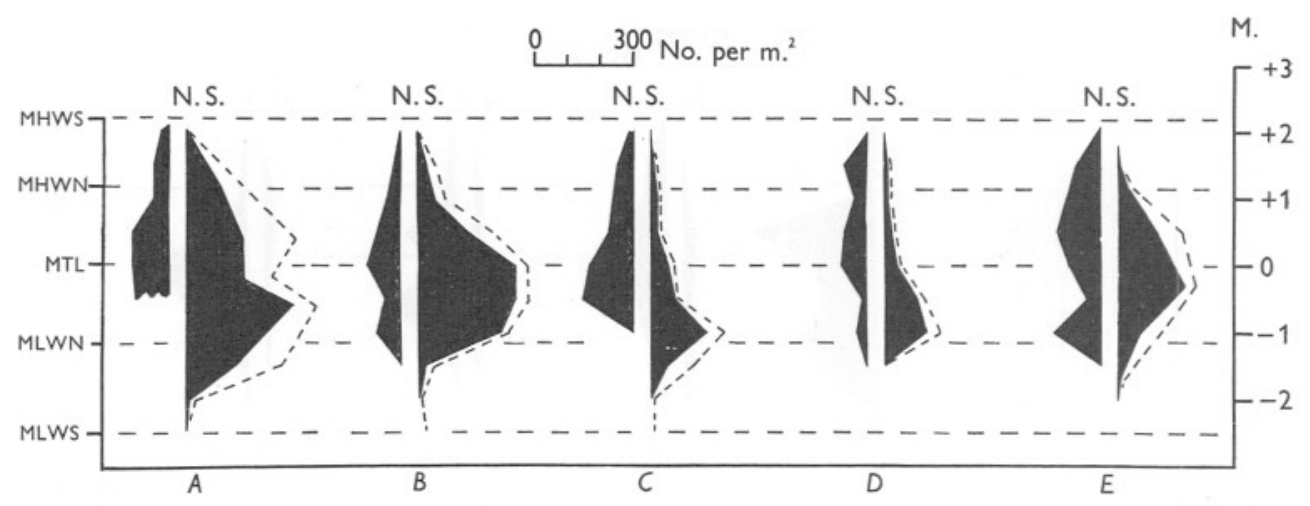

Fig. 5. The distribution of Patella vulgata (black) and total Patella (broken line) on the breakwater.

Patella vulgata (Fig. 5). The upper limit of $P$. vulgata was found to be practically the same on both sides of the breakwater, at $0 . \mathrm{I}-0.2 \mathrm{~m}$. below M.H.W.S. According to previous evidence (Orton, I929; Evans, I947b; Southward, I953) this species is not normally found above M.H.W.N., except on north-facing shaded surfaces, or on rocks receiving considerable waveaction. It would therefore appear that, on the breakwater, the effect of waveaction on the south side is more or less balanced by the effect of the greater shade from the sun on the north side. The moderately dense growth of Fucus spiralis on the north side up to M.H.W.S. may help to maintain the upper limit of Patella on that side by offering further protection from desiccation.

The lower limits differed by about $0.5 \mathrm{~m}$.: on the north side the limit varied from $0.2 \mathrm{~m}$. above, to $0.3 \mathrm{~m}$. below, M.L.W.N., while on the south side it varied from $0.3 \mathrm{~m}$. below M.L.W.N., to M.L.W.S. The occurrence of the lowest lower limit at the western end of the south side supports the view that this difference is due to the wave-action (cf. Southward, I953), but it is possible that the higher lower limit on the north side is more a result of the layer of silt present on the rocks below L.W.N. rather than to the shelter from wave-action itself. 
From Fig. 5 it will be seen that the largest numbers of $P$. vulgata occurred on the south side of each traverse, reaching a maximum towards the western end of the breakwater. In general, this agrees with findings in the Isle of Man, where, except on very steep slopes, the numbers tended to increase with increase in exposure to wave-action (Southward, 1953). However, the differences between the two sides of the breakwater were not very marked, especially on purely limestone substrata. For example, on traverses $C$ and $D$ the greatest numbers found on the north side were $\mathrm{I} 34$ and $76 / \mathrm{m} .{ }^{2}$ respectively, compared with 156 and $130 / \mathrm{m}^{2}$ on the south side. Above M.T.L., in fact, the north-side population was the greater. On the granite substrata of traverse $A$, however, the numbers reached $330 / \mathrm{m} .{ }^{2}$ just below M.T.L., practically twice the population at the same level on the limestone rock, and nearly three times that at the same level on the north side.

The problem of population density in Patella is quite inseparable from that of size, since there is usually a broad inverse correlation between them (Jones, I948; Southward, 1953). The smaller sizes present in wave-beaten situations (Fischer-Piette, 194I, 1948; Evans, I947 b) may therefore be due to the greater numbers present in such places (Southward, 1953). On the breakwater the limpets tended to be larger on the north side, i.e. there was a bigger proportion of the larger size-groups (40-70 mm. in length), and Fig. 6 shows a representative series of histograms for the M.T.L. samples. The size difference was most marked at, and above, M.T.L., the proportion of larger Patella on the south side increasing towards L.W.N. The absence of larger limpets was particularly noticeable on the densely inhabited granite substrata on the south side (Fig. 6A, $B$ ).

The restriction of $P$. intermedia and $P$. aspera to the more wave-beaten places (Fischer-Piette, 1948; Evans, 1947 $a, b$ ) is clearly demonstrated by the limpet samples from the breakwater. On the north side, out of about 2000 specimens examined, only ten specimens of $P$. intermedia and six $P$. aspera were found, and these nowhere exceeded a density of $4 / \mathrm{m} .{ }^{2}$. On the south side these species were present on all traverses, and at certain levels constituted almost half of the total limpet population (see Fig. 5).

$P$. intermedia. The upper limit of this species was a little below that of P. vulgata, varying from $0.2 \mathrm{~m}$. below M.H.w.s. at the western (more exposed) end, to about M.H.W.N. at the eastern end of the south side. The lower limit on the south side was at about M.L.W.N., except on traverse $A$, where the species occurred to $0.3 \mathrm{~m}$. below this. The few specimens that occurred on the north side were found between M.H.W.N. and M.T.L. On the south side the greatest numbers were found around M.T.L., reaching a maximum of $160 / \mathrm{m}^{2}{ }^{2}$ on traverse $A$. The density was generally higher on the granite than on the limestone.

$P$. aspera. On the south side, the upper limit was higher at the western end, where it occurred at M.H.W.N. on traverses $A$ and $B$, compared with M.T.L. on 
traverse $D$. On traverses $A, B$ and $C$ the species was present down to M.L.W.S. and possibly below, but on $D$ it did not occur more than $0.3 \mathrm{~m}$. below M.L.W.N. Of the few specimens found on the north side, one occurred at M.T.L., the others at M.L.W.N. The numbers on the south side were generally greater on the limestone than on the granite, reaching a maximum of $80 / \mathrm{m} .{ }^{2}$ on traverse $C$, just below M.L.W.N.

Gibbula cineraria was the least common of the three species of top-shells found on the breakwater. It occurred only once in the samples, at M.L.W.N. on the south side of traverse $B$, but it seems possible that it may have been present on the north side below the limit investigated (M.L.W.S.).

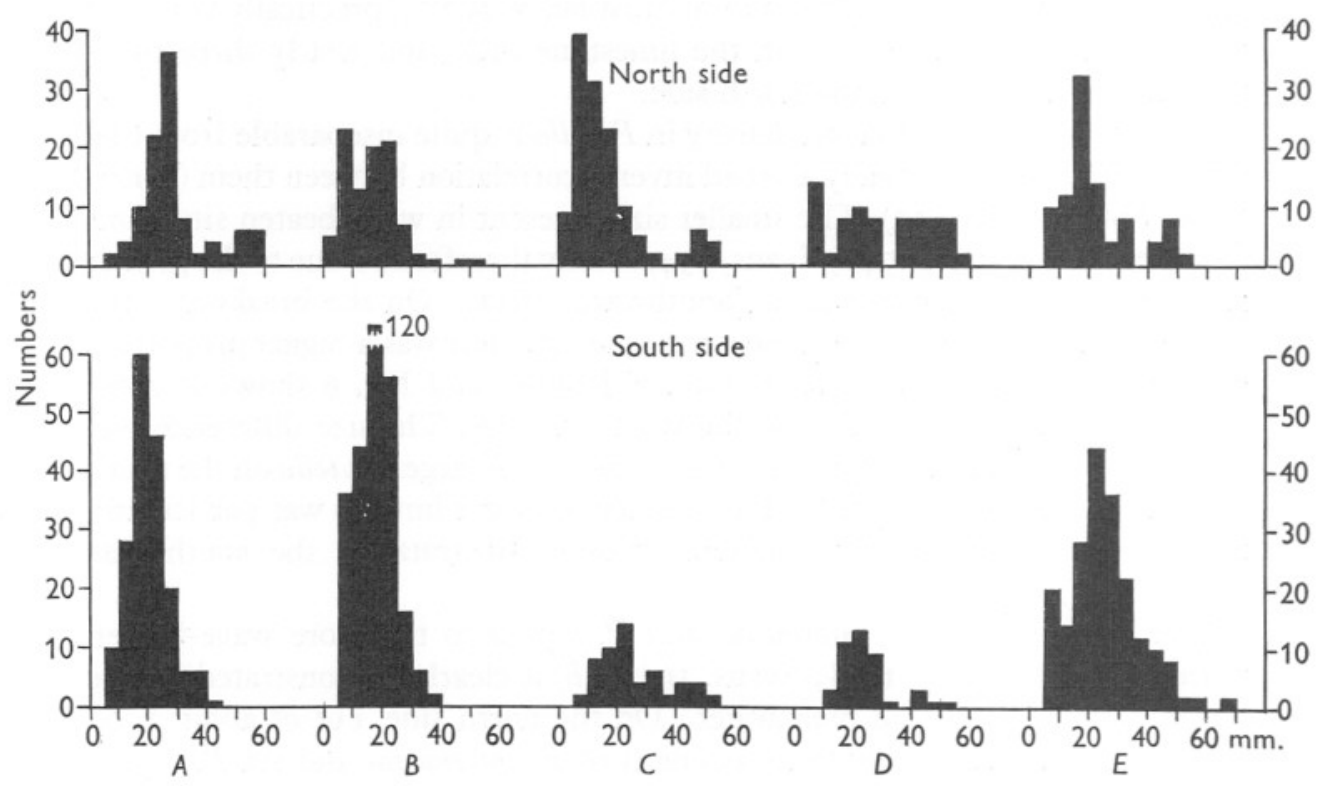

Fig. 6. Frequency distributions, in $5 \mathrm{~mm}$. groups, of $\mathrm{I} \mathrm{m.} .^{2}$ samples of Patella vulgata taken at M.T.L. on each traverse on the breakwater.

G. umbilicalis was the commonest top-shell, but, except for one specimen in a pool at M.H.W.N. on the south side of traverse $D$, it was confined to the north side. It was absent from traverse $A$, sparse on $B$, but commoner on $D$ and $E$, where it reached a density of $15 / \mathrm{m} .{ }^{2}$, and ranged from M.H.W.N. to M.L.W.N. In other places in the Plymouth area it has been found down to M.L.W.S. (Evans, $1947 b$ ).

Osilinus lineatus occurred only on the north side of traverse $E$, between M.H.W.S. and M.H.W.N.

Littorina neritoides. The distribution of this species on the breakwater has been described by Lysaght (194I). In the present work the observations were confined to the quantitative samples on the traverses, and the specimens which 
occur in crevices and pools were ignored. Thus the numbers found in I95I were generally less than those found by Lysaght.

When the crevice-living specimens were omitted it was found that the remaining specimens were associated with Chthamalus, occurring between the shells or inside dead ones. The distribution thus followed that of Chthamalus quite closely (Figs. 4, 7). However, there were a number of differences: the numbers were no higher on granite than on limestone, and the lower limit was approximately $0.5 \mathrm{~m}$. higher than that of Chthamalus.

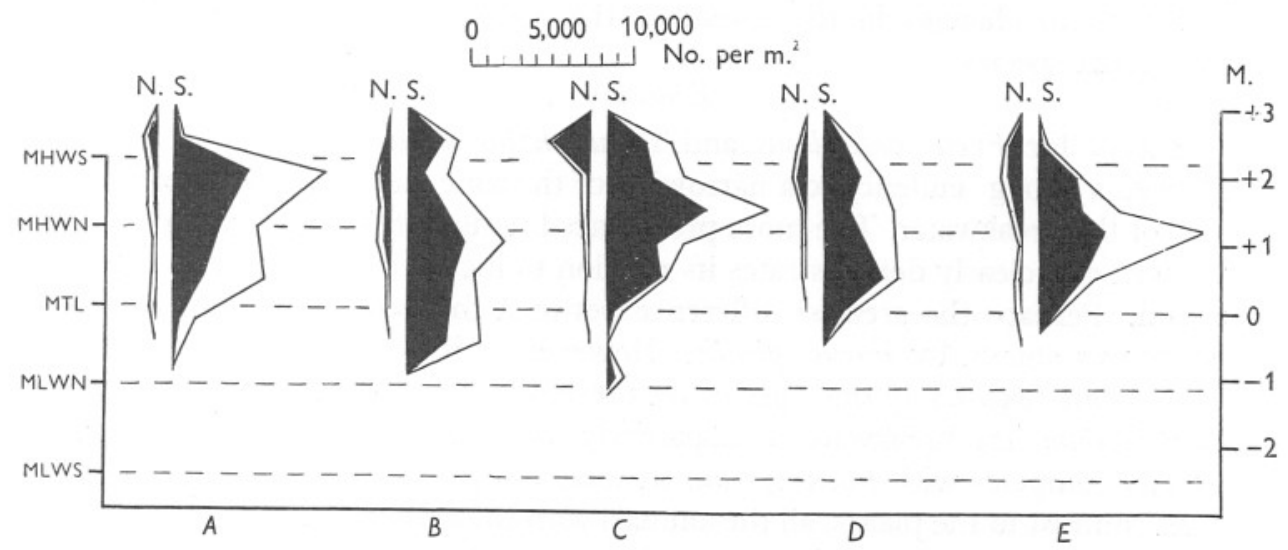

Fig. 7. The distribution of Littorina neritoides $(\mathbf{D})$ and L. saxatilis $(\square)$ on the breakwater.

While Littorina neritoides was the dominant littorinid on both sides of the breakwater, the numbers present on the south side were at least three times as great as those on the north side; the maxima found were $1000 / \mathrm{m} .{ }^{2}$ at E.H.W.S. on the north side of traverse $C$, and $3000 / \mathrm{m} .{ }^{2}$ at M.H.W.N. on the south side of traverse $C$.

L. saxatilis was commonest on the south side of the breakwater, where it constituted half of the littorinid population between M.H.w.S. and M.H.W.N., and reached a density of $3000 / \mathrm{m}^{2}$ on traverse $E$. On the north side the numbers did not reach $500 / \mathrm{m} .{ }^{2}$, but the lower limit was some $0.5 \mathrm{~m}$. lower than that of L. neritoides (Fig. 7).

It is interesting that $L$. neritoides should be the commoner littorinid on both sides of the breakwater since it is usually found in exposed places only (cf. Evans, 1947b). It is possible that there is some factor inimical to $L$. saxatilis on the north side.

\section{Discussion AND CONCLUSIONS}

With the exception of Lichina, found only on the south face, and Osilinus, found only on the north face, all the species investigated were present on both sides of the breakwater. The factors influencing the distribution of Lichina are 
somewhat obscure, but Evans (1947b) has shown some correlation with waveaction; the breakwater evidence, such as it is, would appear to confirm this. Osilinus and the other top-shells were scarce even on the north side of the breakwater. They have little power of attachment, and appear very intolerant of wave-action on steep faces or smooth slopes, where they are in great danger of being swept away. They reach their greatest abundance on flat, broken shores, where they may exist under moderately wave-beaten conditions.

The remaining differences between the two sides of the breakwater were restricted to changes in the extent of the zones, or in the abundance of individual species.

\section{Zonation}

Except for Fucus vesiculosus and Himanthalia lorea, most of the plants showed a strong tendency to a narrowing of the zone on the southern exposed side of the breakwater. The more pronounced nature of this narrowing at the western end clearly demonstrates its relation to increasing exposure to waveaction. Perhaps the greatest difference between the two sides of the breakwater was shown by Fucus spiralis. However, it is possible that the much lower limit reached by this species on the north side reflects the absence of Ascophyllum (the breakwater is apparently too steep for this species) which usually competes with Fucus spiralis in sheltered places.

In contrast to the plants, all the animals with the exception of the top-shells occupied a wider zone on the south side than on the north side. At the same time the zone was wider at the west end of the south face than at the east end. Obviously, increasing wave-action causes an extension of the upper and lower limits of these species, but the relationship does not appear to be a linear one. Thus, the wave-action on the south face has up to Io times the amplitude of that on the north face, while along the south side, the amplitude is some 10-40 \% greater at the western end. Yet the zones may undergo a greater extension between the east and west ends of the south side than between the north and south sides of any traverse. For example, the zone of Chthamalus increases by $20 \%$ between the north and south sides of the breakwater, but increases by the same percentage between the east and west ends of the south side. Similarly, with the littorinids and Patella vulgata, the increase between the east and west ends of the south side is at least equal to, if not greater than, that between the north and south sides. While it is possible that other factors are involved in the case of Patella, we have observed elsewhere that the increase in the wave-action may be out of all proportion to the resulting change in levels. For example, in the Plymouth area, the normal upper limit of Chthamalus, excluding the upper parts of the estuaries, is approximately M.H.W.S., yet even in the most exposed places, where wave-action may have increased more than tenfold, it is rare for the species to extend more than a metre above this level.

A more direct relationship to increasing wave-action is shown by the upper 
limit of Patella aspera (Southward, I953) and possibly of $P$. intermedia, but this could not be demonstrated on the breakwater since too few specimens were found on the north side.

\section{Abundance}

The effect of wave-action on algae is comparatively well known (Stephenson, 1939; Evans, 1947b), and the breakwater evidence confirms previous investigations. Not only was the plant cover higher on the north side, but the maximum fucoid population occurred at its eastern end, the area with the least exposure to wave-action. In contrast, the lowest cover of all the species of plants investigated was found at the western end of the south side, the area of maximum wave-action.

The relationship of the numbers of the animals to wave-action is not quite so clear. The barnacles were most numerous towards the western end of the south face, but with Balanus perforatus and B. crenatus, which occur also in sheltered situations, this was probably an effect of the sparser plant cover. The numbers of Chthamalus, however, were almost directly related to the extent of the wave-action, and even the few specimens of Balanus balanoides present on the breakwater were commonest in the region of maximum waveaction. The present work offers no reason why the barnacles should increase in number with increasing wave-action, but from previous work it seems to be due to a greater initial settlement of larvae (Hatton \& Fischer-Piette, 1932). It has been suggested that the increased water movement brings more food to the animals (Moore, 1935) and this may help to maintain the initial density (Southward, 1953).

The abundance of Patella vulgata is affected by the nature and amount of the plant cover (Fischer-Piette, I948; Jones, I948; Southward, I953), which can provide both shelter and food, and large populations may exist both on comparatively bare but wave-beaten places and in comparatively sheltered but weed-grown places. In both habitats there appears to be a higher initial settlement of spat (Hatton, 1938; Southward, 1953), but the rate of growth is apparently greater in the algal-covered areas, hence the higher proportion of larger sizes in such places (Fischer-Piette, 194I, 1948).

The numbers of many intertidal organisms are affected by the nature of the substratum. Thus, on the breakwater, Chthamalus stellatus, Patella vulgata and $P$. intermedia all showed greater numbers on the rough granite than on the smoother limestone. It is possible that this is partly an effect on the settlement, since barnacles are well known to settle more densely on rough surfaces. It is also possible, with the limpets, that the rougher surface (of both the granite and the large barnacle population thereon) may restrict locomotion (Jones, I948), thus reducing the feeding radius, and permitting the maintenance of a large population.

In conclusion, we can, on the evidence from the breakwater, divide up the 
organisms dealt with into three groups according to their relations to waveaction. First, there are those species to which wave-action is unfavourable, and which show it by a narrowing of their zone (either a fall in the upper. limit, or a rise in the lower limit, or both) and a reduction in their numbers. These are, in approximate order of decreasing sensitivity: Osilinus lineatus, Gibbula umbilicalis, Pelvetia canaliculata, Fucus spiralis, Laminaria saccharina, Fucus serratus, Laminaria digitata and Fucus vesiculosus. Then there are those species to which wave-action appears favourable, since under its influence their zone is widened and their numbers increased: these are: Porphyra umbilicalis, Lichina pygmaea, Chthamalus stellatus, Patella intermedia, P. aspera, Littorina neritoides and L. saxatilis. Finally, there are some species for which the breakwater evidence is inconclusive: Himanthalia lorea, Rhodymenia palmata, Balanus perforatus, B. crenatus and Patella vulgata.

\section{SUMMARY}

This paper describes an investigation into the effects of wave-action on the distribution, zonation and numbers of the commoner intertidal plants and animals living on the Plymouth breakwater.

Comparison of observations of wave-action on the breakwater with local wind records produces an exposure index for the year of approximately $35 \%$ which, although similar to a previously calculated index, is much below similarly derived indices for places in the Isle of Man. It would appear that swells and refracted waves are more important at Plymouth.

The wave-action observations showed great differences between the two sides of the breakwater, the height reached by the wash on the south side being more than ro times as great as that on the north side. At the same time, the wash on the south side was found to be some $10-40 \%$ greater at the western end than at the eastern end.

The distribution and abundance of the commoner plants and animals is described and discussed in relation to tide level and wave-action.

Most of the plants, with the exception of Lichina, showed their greatest abundance and widest zone on the north face, particularly at its eastern end, which is probably the most sheltered point on the breakwater. Himanthalia lorea and Rhodymenia palmata, however, showed little differences between the two sides of the breakwater.

The majority of the animals, most notably Chthamalus stellatus and Patella intermedia, were favoured by wave-action, the numbers being greater and the zone wider on the south side, and especially at its western end, the most wave-beaten part of the whole breakwater. The top-shells, however, were commonest on the north side. The evidence for Patella vulgata was inconclusive, but tended to confirm previous evidence that this species is abundant in both weed-grown and wave-beaten places, but that the zone is wider and the shell smaller in the latter situations. 


\section{REFERENCES}

Admiralty Tide Tables for 1951, European Waters, 1950. Hydrographic Department, Admiralty, London.

Colman, J., I932. A statistical test of the species concept in Littorina. Biol. Bull., Wood's Hole, Vol. 62, pp. 223-43.

- 1933. The nature of the intertidal zonation of plants and animals. F. Mar. biol. Ass. U.K., Vol. I8, pp. 435-76.

Evans, R. G., I947a. The intertidal ecology of Cardigan Bay. F. Ecol., Vol. 34, pp. 273-309.

- I $947 b$. The intertidal ecology of selected localities in the Plymouth neighbourhood. F. Mar. biol. Ass. U.K., Vol. 27, pp. 173-218.

Fischer-PietTe, E., I938. The concept of species and geographical isolation in the case of North Atlantic Patellas. Proc. Linn. Soc., Lond., Vol. I50, pp. 268-75.

- 194I. Croissance, taille maxima, et longévité possible de quelques animaux intercotidaux en fonction du milieu. Ann. Inst. océanogr. Monaco, T. 2I, pp. I-28.

— I948. Sur les éléments de prospérité des Patelles et sur leur specificité. F. Conchyliol., T. 88, pp. 45-96.

Hatton, H., 1938. Essais de bionomie explicative sur quelques espèces intercotidales d'algues et d'animaux. Ann. Inst. océanogr. Monaco, T. 17, pp. 24I-348.

Hatton, H. \& Fischer-Piette, E., I932. Observations et expériences sur le peuplement des côtes rocheuses par les Cirripèdes. Bull. Inst. océanogr. Monaco, No. 592, pp. I-I5.

Jones, N. S., I948. Observations and experiments on the biology of Patella vulgata at Port St Mary, Isle of Man. Proc. Lpool biol. Soc., Vol. 56, pp. 60-77.

KItching, J. A., 1935. An introduction to the ecology of intertidal rock surfaces on the coast of Argyll. Trans. roy. Soc. Edinb., Vol. 58, pp. 35I-74.

LYSAGHT, A. M., I94I. The biology and trematode parasites of the gastropod Littorina neritoides (L.) on the Plymouth Breakwater. F. Mar. biol. Ass. U.K., Vol. 25, pp. 4I-67.

Marine Biological Association, i93i. Plymouth Marine Fauna, and ed.

Moore, H. B., I935. The biology of Balanus balanoides. IV. Relation to environmental factors. F. Mar. biol. Ass. U.K., Vol. 20, pp. 279-307.

Newton, L., I93I. A handbook of the British Seaweeds. London.

OrTON, J. H., I920. Sea-temperature, breeding, and distribution in marine animals. F. Mar. biol. Ass. U.K., Vol. I2, pp. 339-66.

- I929. Observations on Patella vulgata. Part III. Habitat and habits. F. Mar. biol. Ass. U.K., Vol. I6, pp. 277-88.

SouthWARD, A. J., I953. The ecology of some rocky shores in the south of the Isle of Man. Proc. Lpool biol. Soc., Vol. 59, pp. I-50.

SOUthWARD, A. J. \& CRISP, D. J., I952. Changes in the distribution of intertidal barnacles. Nature, Lond., Vol. 170, pp. 4I6-17.

Stephenson, T. A., I939. The constitution of the intertidal fauna and flora of South Africa. Pt. I. F. Linn. Soc. (Zool.), Vol. 40, pp. 487-536. 